\title{
ASPECTOS PROCESALES DE LA DECLARATORIA DE INTERDICCIÓN POR DISCAPACIDAD MENTAL ABSOLUTA
}

Procedural aspects of the declaration of mental disability absolute ban

\author{
Cesar Andrés Tirado Pertúz ${ }^{117}$ \\ Carlos Eduardo García Granados ${ }^{118}$
}

Fecha de recepción: 12 de abril de 2018

Fecha de aceptación: 22 de mayo de 2018

Sumario: Resumen, Palabras Claves, I. Introducción, II. Protección al discapacitado mental absoluto III. El proceso de interdicción, 3.1. El interdicto 3.2. La Demanda, 3.3. Las Medidas de Carácter Personal, 3.4. Trámite Judicial, 3.5. Las Calidades del Curador, V. Discusión. VI. Conclusiones, Bibliografía.

\footnotetext{
117 Abogado de la Universidad de Cartagena, Especialista en Derecho de Familia, Universidad Libre de Colombia - Sede Barranquilla. Abogado Asesor en la Sala Civil - Familia del Tribunal Superior de Popayán - Cauca. http://orcid.org/0000-0002-8784-3347. E-mail: cesar.tirado@hotmail.com

118 Abogado de la Universidad de Cartagena. Magister en Derecho, Universidad de Cartagena. Juez Sexto de Familia de Cartagena. E-mail: cegg136896@hotmail.com
} 
Cesar Andrés Tirado Pertúz, Carlos Eduardo García Granados

\section{COMO SE CITA ESTE ARTíCULO (APA 6)}

Tirado Pertúz, Cesar Andrés \& García Granados, Carlos Eduardo (2018). Aspectos procesales de la declaratoria de interdicción por discapacidad mental absoluta. Revista Jurídica Mario Alario D’Filippo, Vol. X, №. 20, pág. 154 - 172

\section{RESUMEN}

En lo sustancial vemos que la Constitución Política de 1991 trajo consigo una serie de cambios en las estructuras socio-culturales que dieron origen a muchas normas, entre las cuales destacamos para este trabajo en particular la Ley 1306 del 2009, que surge como una respuesta a la necesidad de mejorar las condiciones jurídicas de los incapaces por discapacidad mental y adaptarlas. En lo jurídico, encontramos que para la declaratoria de interdicción por discapacidad mental se debe acudir a un proceso de jurisdicción voluntaria. En este trabajo nos proponemos analizar paso a paso el proceso judicial para la declaratoria de interdicción por discapacidad mental, a efectos de verificar si este es lo suficientemente eficaz para proteger los derechos de los incapaces absolutos.

\section{Palabras Claves}

Discapacidad Mental, Juez de Familia, Proceso de Interdicción, Curador, Derechos Humanos.

\section{ABSTRACT}

In essence it is undisputed that the constitution of 1991 brought positive discrimination as a factor in the whole society, in turn a series of changes in the socio- cultural structures that gave place to different laws among which we emphasize the act 1306 of 2009 that comes up as a response to the need for improvement and update of the legal conditions of the incompetents people caused by mental disabilities. In the juridical we find a number of drawbacks as to be declared legally incompetent because of mental disabilities must go to family court and follow a process of voluntary jurisdiction. In this paper, we analyze step by step the judicial process to be declared legally incompetent because of mental disability, in order to verify whether this is efficient enough to protect the rights of absolute incompetent.

\section{Keys Words}

Mental Disability, Family Judge, Interdiction Process, Curator, Human Rights. 


\section{INTRODUCCIÓN}

La Ley 1306 de 2009,, ${ }^{119}$ en concordancia con algunos aspectos de la Ley 1098 de $2006^{120}$ han establecido para las personas con discapacidad mental, una categorización que las configura como una población de especial protección por parte del Estado y en la sociedad, consignando en ellas un amplio catálogo de derechos fundamentales y demás disposiciones que permite ejecutar medidas de protección especial a los discapacitados. Cuando judicialmente se puede lograr la declaración de Interdicción por discapacidad mental; nos preguntamos entonces ¿̇el proceso de declaración de interdicción por discapacidad mental, tal como está planteado en la legislación colombiana, protege los derechos de los incapaces?

Hernán Fabio López Blanco en el Tomo II de su obra Instituciones de Derecho Procesal Civil Colombiano hace una crítica a los juicios de interdicción diciendo que "(...) la verdad sea dicha, a estos juicios únicamente se acude cuando existen fuertes intereses económicos de por medio y se quiere separar al demente de la administración de los bienes.", y en la práctica, pareciera ser que lo expuesto por el ilustre tratadista marcara una tendencia referente a cuando se debe acudir al proceso judicial, llegando a la conclusión que se acude al mismo solo cuando existen intereses económicos y que el verdadero objetivo de los procesos de declaración de interdicción por discapacidad mental es lograr la protección de los bienes y derechos de carácter patrimonial más que la vida e integridad de los interdictos a través de la curaduría.

Habría que preguntar ¿Por qué solo cuando existe interés económico se acude al proceso de interdicción?; Aunque, teóricamente, la separación de la administración y disposición de sus bienes y derechos, supone una medida de protección al discapacitado, pues se le brinda lo necesario para que su curador garantice su vida digna y su representación legal, la eficacia del proceso judicial es una necesidad, y por esta razón la investigación que se propone tiene como objetivo principal analizar las herramientas jurídicas del procedimiento ante los jueces de familia para la declaratoria de interdicción por discapacidad mental, para lo cual se logró una revisión jurisprudencial y legislativa. De igual forma nos circunscribimos al Código Civil, el (hoy derogado) Código de Procedimiento Civil, el Código General del Proceso, la Ley 1306 del 2009, la jurisprudencia de la Corte Constitucional sobre la interdicción por discapacidad mental y algunos tratados internacionales sobre la materia como base teórica de esta investigación.

En el Código Civil se distingue la capacidad jurídica de la capacidad legal, consistiendo la primera en la aptitud que corresponde a toda persona para ser sujeto de derechos y obligaciones y la segunda en la habilidad que la Ley reconoce para intervenir en el comercio jurídico, por si misma

\footnotetext{
119 Por la cual se dictan normas para la Protección de Personas con Discapacidad Mental y se establece el Régimen de la Representación Legal de Incapaces Emancipados.

120 Por la cual se expide el Código de la Infancia y la Adolescencia.
} 
y sin ministerio o autorización de otras. Según nuestro derecho positivo, la capacidad legal, que constituye uno de los requisitos necesarios para la validez de las declaraciones de voluntad, la tiene toda persona excepto aquellas que la ley declara incapaces. Igualmente en la parte procesal, tanto el Código de Procedimiento Civil y el Código General del Proceso regulan el trámite correspondiente dentro de los procesos de jurisdicción voluntaria. En la ley 1306 del 2009 que según su artículo 4ㅇ “(...) se complementa con los Pactos, Convenios y Convenciones Internacionales sobre Derechos Humanos relativos a las personas en situación de discapacidad aprobados por Colombia, que integran el bloque de constitucionalidad (...)".

\section{Protección al discapacitado mental absoluto}

En general, siempre se ha planteado la necesidad de representación de quien no se considera capaz ante la sociedad, es como una forma de proteger el "estatus quo del contrato social", suponemos que los menores de cierta edad no pueden tener una madurez psicológica para realizar ciertos actos, lo cual va a depender mucho de las estructuras socio-culturales y los marcos jurídicos de cada estado. Pero también se ha entendido que existen varios factores de incapacidad como consecuencia del ejercicio del poder de turno y sus intereses, es así como en esta institución se ve en todas las culturas antiguas como la griega o la babilónica. Por ejemplo, en Roma antigua se decía que las mujeres, por su condición de mujer, debían estar representadas por el pater familia, bien sea su esposo o su padre biológico o por adopción. La idea de protección a los disminuidos físicos y mentales nos viene desde el derecho Romano, en el cual existieron las curatelas y las tutelas pero estaban dirigidas a la protección del patrimonios del furiosi o mente captis, a los sordos a los mudos y en general a los que tuvieran algún tipo de enfermedad grave, o a los pródigos, se les nombraba un tutor o curador quien en general tenía la Negotiorum gestio $^{121}$ y la Interposición de la auctoritas ${ }^{122}$, (Echeverría, 2010)

Igualmente sucedía en el código Napoleónico que estableció en su artículo 489: "el mayor de edad que esté en un estado de imbecilidad, de demencia o de furor debe ser sujeto a interdicción, aun cuando ese estado presente intervalos lucidos" (Quiroz, 2014). Estos términos han sido producto de la psiquiatría de la época. Esta idea paso directamente al Código Civil de don Andrés bello y por ende al Código Civil de la Unión que todavía hoy -aunque reformado en muchas de sus partes- tenemos en Colombia. Para la Ley 57 de 1887, la enfermedad mental es la que altera la voluntad de una persona porque la destruye o porque la vicia, y en consecuencia son causales de incapacidad civil, especialmente de incapacidad para los negocios jurídicos, cuyo núcleo

121 Gestión de los negocios del pupilo en nombre propio y también en la administración de sus bienes. Tiene la posesión de los bienes 122 acto complementario realizado por el tutor para dar eficacia al negocio realizado por el pupilo mayor de siete años. Mediante este acto coopera para dar validez o eficacia al acto del pupilo.

Determinados actos exigen la asistencia del tutor. 
esencial es la existencia de una voluntad sana y libre (Valencia Zea y Ortiz, 1994En aquella época, nuestro estatuto sustantivo civil establecía en el artículo 545 que a su vez había sido reformado por la Ley 95 de 1890, art. 8을

El adulto que se halle en estado habitual de imbecilidad o idiotismo, de demencia o de locura furiosa, será privado de la administración de sus bienes, aunque tenga intervalos lúcidos. La curaduría del demente puede ser testamentaria, legítima o dativa.

A su turno el artículo 428 de la época establecía que:

Las tutelas y las curadurías o curatelas son cargos impuestos a ciertas personas a favor de aquellos que no pueden dirigirse a sí mismos, o administrar competentemente sus negocios, y que no se hallen bajo potestad de padre o marido, que pueda darles la protección debida.

Las personas que ejercen estos cargos se llaman tutores o curadores, y generalmente guardadores.

La discapacidad mental se continuó manejando conforme a las arcaicas normas derivadas del derecho romano. Con la Declaración Universal de Derechos Humanos de 1948, con ocasión de la reivindicación general de los derechos y las víctimas de las guerras mundiales, que cobró gran importancia en el derecho moderno, y es así como la misma Corte Constitucional en la sentencia C-478 del 2003 dijo que:

"Al término de la segunda guerra mundial, con el surgimiento del derecho internacional de los derechos humanos, se produjo un importante cambio en la concepción de la problemática de las personas con grave discapacidad física o mental por cuanto se le dejó de percibir como un asunto exclusivamente médico o patológico, objeto de regulación y estudio por el derecho privado, para convertirse en un tema vinculado directamente con el principio de dignidad humana y de la órbita de aplicación, en especial, del derecho laboral y de la seguridad social. Desde entonces, mediante diversas fuentes del derecho internacional público, e incluso en algunas disposiciones de derecho interno, se ha intentado precisar el contenido y alcance de la noción de discapacidad, labor que ha resultado ser particularmente compleja por cuanto se alude con frecuencia a diversos términos, sin que las fronteras entre todos ellos resulten ser siempre tan exactas y precisas como se quisiera. Así pues, se han empleado términos como retrasados mentales, impedidos, inválidos, y a partir de la década de los ochenta, discapacitados. (Corte Constitucional C-478 del 2003 M.P. Dra. Clara Inés Vargas Hernández.)

En Colombia, el fenómeno de la Constitucionalización del derecho implica una variación en sus fuentes de producción jurídica, ya que habrá que buscar en el bloque de constitucionalidad primero y luego en las demás normas de orden nacional. En el caso particular, son muchas las instituciones mundiales que promueven la protección a la personas con discapacidades, como es el caso de la Convención sobre la protección de Derechos a Personas con Discapacidad, de las Naciones Unidas, incorporada en nuestro ordenamiento mediante la ley 1346 del 2009 que le da status constitucional a la ley 1306 de ese mismo año. 
Nuestro ordenamiento Civil en este sentido debe acompasarse a la principialística y axiología constitucional que trajo consigo la Carta de 1991, y en consecuencia con el ejercicio positivo que le toca al estado representado en sus tres ramas de poder público, la Legislativa con la promulgación de leyes y actos legislativos, la Ejecutiva con la realización de políticas públicas para el mejoramiento de infraestructura para discapacitados y programas de promoción social a estos; y el Poder Judicial a través de la interpretación favorable y constitucional de las acciones tendientes a la protección de los intereses y derechos fundamentales de los declarados interdictos. De allí que nos hayamos interesado en este estudio, pues se trata de un aspecto inexplorado por la doctrina y ricamente analizado por la jurisprudencia constitucional. Entramos ahora a analizar el proceso de interdicción.

\title{
III. El proceso de interdicción
}

\section{El pretendido interdicto}

Para velar por los intereses de las personas que se encuentran en circunstancias de discapacidad mental, además del decreto de interdicción, dispuso el legislador la existencia de la representación legal, en virtud de la cual se coloca a estos sujetos al cuidado de ciertas personas revestidas de facultades para actuar en su nombre y para vincularse en los efectos que de estos actos se derivan, como si hubieran contratado ellos mismos. Tales personas son los guardadores o curadores, cuyo nombramiento y funciones se encuentran regulados por el art. 52 y subsiguientes de la Ley 1306 de 2009, que preceptúa:

\begin{abstract}
A la persona con discapacidad mental absoluta mayor de edad no sometido a patria potestad se le nombrará un curador, persona natural, que tendrá a su cargo el cuidado de la persona y la administración de sus bienes.

El curador es único, pero podrá tener suplentes designados por el testador o por el Juez. Las personas que ejercen el cargo de curador, los consejeros y los administradores fiduciarios de que trata el presente Capítulo, se denominan generalmente guardadores y la persona sobre la cual recae se denomina, en general, pupilo.
\end{abstract}

Es importante anotar que la discapacidad mental es diferente a la inhabilidad. Si bien el Legislador aparentemente incluyó ambos sujetos en una misma categoría -la de discapacidad mental-, es necesario considerar las diferencias entre el discapacitado mental absoluto y el inhábil, quien puede ser capaz y no sufrir ninguna enfermedad mental grave pero, por determinadas circunstancias, se lo inhabilita para realizar ciertos negocios jurídicos con el fin de proteger su patrimonio, como sucede, por ejemplo, con los inmaduros negóciales, los pródigos o anteriormente denominados disipadores. Así, en el nuevo régimen, al inhábil se le reconoce un amplio margen de maniobra, mayor al de la persona con discapacidad mental absoluta, y deja de aplicársele el régimen de interdicción, inclusive. En este trabajo nos remitiremos al Discapacitado mental absoluto. 
La Ley 1306 de 2009 junto con la Ley 1098 de 2006 han establecido para las personas con discapacidad mental, una categorización que las configura como una población de especial protección por parte del Estado y en la sociedad, consignando en ellas un catálogo de derechos fundamentales y demás disposiciones que permite ejecutar esas medidas y dentro de ellas, judicialmente se puede lograr la declaración de Interdicción. Dentro de estas disposiciones podemos destacar las siguientes:

Artículo 60 La Función de Protección. La protección del sujeto con discapacidad mental corresponde y grava a toda la sociedad, pero se ejercerá de manera preferencial por: a) Los padres y las personas designadas por estos, por acto entre vivos o por causa de muerte. b) El cónyuge o compañero o compañera permanente y los demás familiares en orden de proximidad, prefiriendo los ascendientes y colaterales mayores y los parientes consanguíneos a los civiles. c) Las personas designadas por el juez. d) El Estado por intermedio de los funcionarios e instituciones legítimamente habilitadas..." "Artículo 17. El Sujeto con Discapacidad Mental Absoluta. Se consideran con discapacidad mental absoluta quienes sufren una afección o patología severa o profunda de aprendizaje, de comportamiento o de deterioro mental. (Negrillas fuera del texto)

Sobre la protección especial que ameritan las personas que por su especial condición necesitan de otras que las representen por no poder ellas desempeñarse por sí mismas, ha dicho la Corte Constitucional en Sentencia T-941 del 2005:

4. El deber del Estado de otorgar una protección especial a las personas que por padecer una enfermedad mental se encuentran en circunstancias de indefensión y debilidad manifiesta. El artículo 13 de la Constitución Política contempla que el Estado tiene el deber de proteger a aquellas personas que por su condición económica, física o mental, se encuentren en circunstancias de debilidad manifiesta. De igual forma el artículo 47 Superior consagra que el Estado debe adelantar una política de previsión, rehabilitación e integración social para los disminuidos físicos, sensoriales y psíquicos, quienes deben recibir una atención especializada. En este orden de ideas, la Constitución prevé una protección especial para a aquellas personas que por su estado físico o mental tengan la calidad de disminuidos y como consecuencia de ello se encuentren en condiciones de debilidad manifiesta.

Al respecto, la Corte en sentencia T-378 de 1997, MP. Eduardo Cifuentes Muñoz, señaló:

En distintas sentencias, la Corte Constitucional ha indicado la necesidad de brindar un trato especial a las personas discapacitadas y ha señalado que la omisión de ese trato especial puede constituir una medida discriminatoria. Ello, por cuanto la no aplicación de la diferenciación positiva en el caso de las personas discapacitadas permite que la condición natural de desigualdad y desprotección en que se encuentran se perpetúe, situación que les impide, entonces, participar e integrarse en las actividades sociales, para poder así ejercer sus derechos y responder por sus obligaciones. 
Así mismo, la Corte Constitucional en sentencia T-307 de 1993, MP. Eduardo Cifuentes Muñoz, estimó que las normas legales deben ser interpretadas de manera tal que favorezcan, dentro de los límites de lo razonable, a las personas minusválidas. A este respecto, la Corte indicó:

La interpretación de la ley, a partir de los presupuestos de la normalidad, en consecuencia, no es apropiada cuando se propone aplicarla a los disminuidos psíquicos, pues, en su caso se torna imperativo con miras a su integración social extraer los elementos de la misma que tiendan a su mayor beneficio y excluir los que a la luz de su particular situación puedan resultar irrazonables.

En sentencia T-1221 de 2004, MP. Alfredo Beltrán Sierra, la Corte consideró que se debe otorgar a los minusválidos un trato desigual más favorable y por consiguiente preferir y aplicar las normas que los protegen sobre las normas de carácter general, en razón del "carácter tuitivo de las

primeras". En la citada sentencia la Corte indicó que para que se haga efectivo el propósito contenido en el artículo 47 de la Constitución Política, el legislador debe diseñar normas de especial protección y los operadores jurídicos aplicar "las disposiciones vigentes, a través de una interpretación legal, dirigida a lograr que el anotado propósito superior sea viable."

En general, el trámite de interdicción deberá adelantarse ante el juez de familia del domicilio del presunto interdicto, siendo este un proceso de jurisdicción voluntaria ya que no hay demandado. La Corte Constitucional ha explicado que:

Este proceso se adelanta ante un juez de familia, quien previa revisión de la solicitud y agotamiento del trámite, ordenará que una persona idónea (familiar o profesional), le administre el patrimonio a quien está en situación de discapacidad mental y ejerza sus derechos y obligaciones. Es un proceso de jurisdicción voluntaria, que no busca resolver un litigio, ni controvertir, ni obtener un derecho, sino que se declare que una persona no está en plenas condiciones mentales para desempeñarse por sí misma, con el objeto de evitar que se aprovechen de su condición y realicen actuaciones o negocios que puedan afectarle. (Corte Constitucional sentencia T-026 de 2014 M.P. Dr. Nilson Pinilla Pinilla)

\section{De la demanda}

Resulta de trascendental importancia señalar que el objeto del proceso es decretar la interdicción del discapacitado mental absoluto y en consecuencia privarlo del ejercicio de sus derechos civiles, de la administración y disposición de sus bienes y brindarle la protección necesaria para que éste viva dignamente, asignándole un guardador o curador, para que administre sus bienes y se ocupe de su cuidado personal; en general la demanda debe contener los requisitos generales del artículo 82 del C.G.P, y la podrá presentar cualquier persona, ya que la titularidad no se encuentra cualificada y que se entiende que se trata de un tema de interés general, de allí que la ley 1306 del 2009 estableció en el artículo 18 que: 
Corresponde al Instituto Colombiano de Bienestar Familiar, por intermedio del Defensor de Familia, prestar asistencia personal y jurídica a los sujetos con discapacidad mental absoluta de cualquier edad, de oficio o por denuncia que cualquier persona haga ante la Entidad. (...)

Disposición esta que debe interpretarse en concordancia con el artículo 25 de la misma ley que establece un orden que es enunciativo, más no taxativo.

Además, en un acápite especial se deben citar los nombres y las direcciones de los parientes del presunto interdicto en cumplimiento del artículo 61 del C.C. en concordancia con lo estipulado por el artículo 586 del CC, que su numeral 3o se dispone "En el auto admisorio de la demanda se ordenará emplazar, en los términos previstos en este código (...)".

Igualmente y aún más importante, deberá acompañarse de un certificado expedido por un médico psiquiatra o neurólogo sobre el estado del presunto interdicto, conforme a lo establecido por el artículo 28 de la ley 1306 de 2009 que estipula que:

En todo proceso de interdicción definitiva se contará con un dictamen completo y técnico sobre la persona con discapacidad mental absoluta realizado por un equipo interdisciplinario compuesto del modo que lo establece el inciso 20 del artículo 16 de esta ley. En dicho dictamen se precisarán la naturaleza de la enfermedad, su posible etiología y evolución, las recomendaciones de manejo y tratamiento y las condiciones de actuación o roles de desempeño del individuo.

Lo propio también lo recoge el numeral cuarto del Art. 586 del CGP. Sobre lo anterior la Corte Constitucional mediante sentencia T-1103 de 2004 se ha manifestado en el sentido de que:

El acompañamiento de un certificado médico a una demanda en la que se solicita que una persona sea declara interdicta por demencia, no constituye una mera formalidad exigida por la ley procesal para la admisión de una demanda de esta naturaleza, sino que está llamado a cumplir fines específicos como son (i) constituye un soporte probatorio insustituible para que el juez competente tenga los elementos de juicio necesarios para proveer sobre la admisión de una demanda de interdicción; $y$, (ii) se erige en una garantía fundamental para el demandado, dado que no todas las personas deben soportar un proceso de esta naturaleza, sino solamente aquellas sobre las cuales se acredita una condición de discapacidad que amerite, por lo menos, la apertura del proceso. Es por ello, que el certificado médico exigido por la ley, como requisito para acompañar la demanda de interdicción, no puede suplirse con otros medios probatorios, como por ejemplo los testimonios, como equivocadamente lo sostiene la accionada; $\underline{\text { ni tampoco }}$ por epicrisis o resúmenes finales de historias clínicas. Nótese, como según las normas que regulan la ética médica, el certificado médico es el documento que acredita el estado de salud de una persona, constituyéndose en la prueba técnica o pericial que por anticipado debe llevarse al proceso a fin de darle soporte a la solicitud de interdicción, certificado que según se exige debe ser expedido bajo la gravedad del juramento, el cual se entiende prestado con la sola firma. Lo anterior no significa, sin embargo, que en el curso del proceso, el juez no pueda valorar la prueba 
pericial junto con otras, tal y como lo ha considerado de vieja data la jurisprudencia civil nacional. De igual manera, la Sala considera que el mencionado documento científico DEBE SER RECIENTE, por cuanto es común que las enfermedades mentales evolucionen; incluso, en algunos casos se curan, o al menos, sus síntomas se pueden tratar mediante el suministro de medicamentos, sin que la persona tenga que ser sometida a internación en un centro de reposo y sin que pierda realmente sus facultades de discernimiento." (Subrayas fuera del texto) Igualmente el ICBF emitió concepto para estos casos en lo que concluye que en "estos procesos deben acompañarse de un certificado de un médico psiquiatra o neurólogo, sobre el estado del presunto interdicto, que establezca las características del paciente, el diagnóstico de la enfermedad y con las consecuencias de la capacidad del paciente para administrar sus bienes, y el tratamiento del mismo. (Instituto Colombiano de Bienestar Familiar - ICBF; concepto 29 de 2014.)

Resultan ser estos dos elementos especialísimos de citar a los parientes y el acompañamiento del certificado médico reciente, las principales causales de inadmisión de estos procesos en los estrados judiciales, como el que uno de los autores regenta. Basta llegar a un juzgado de familia y revisar los procesos de interdicción, encontrándose autos casi "automáticos" inadmitiendo las demandas por cualquiera de estas dos falencias o en algunos casos, ambas. Resulta muy frecuente encontrar demandas con tan solo la historia clínica, siendo que, como vemos, este documento no puede reemplazar el certificado médico.

\section{De las medidas de carácter personal.}

En los procesos de interdicción se pueden solicitar medidas tendientes a proteger la integridad del discapacitado mental o sus bienes; no se trata de medidas cautelares sino de las llamadas medidas personales, que son aquellas que se refieren a las personas que son parte del proceso; en estos casos el juez podrá ordenar el internamiento del discapacitado en una institución especializada (Ley N¹306, 2009, arts. 22), podrá decretar la interdicción provisional (Ley N¹306, 2009 , art. 27) y designarle un curador provisorio en tanto concluya el proceso judicial, y en general podrá decretar cualquier medida que considere necesaria para proteger al discapacitado mental conforme a lo establecido en el artículo 42 de la ley 1306 de 2009, que en lo pertinente establece que “(...)También se podrán decretar las medidas de protección personal de quien se encuentre con discapacidad mental que el Juez considere necesarias (...)"; por ejemplo, oficiar a las entidades bancarias, a las oficinas de registro de instrumentos públicos, entre otras, mismas que recoge el art. 598, numeral 5, literal f) del CGP.

\section{Del trámite judicial.}

Luego de verificados los requisitos de la demanda, el juez deberá admitirla y ordenar las medidas que considere tendientes a la protección del sujeto discapacitado; ordenará la notificación al Ministerio Público para que intervenga en el proceso, ya que su intervención es obligatoria conforme a lo normado en el artículo 70 de la ley 1306 del 2009. Igualmente se ordenará citar a los parientes cercanos del presunto interdicto citados en la demanda conforme al artículo 61 del 
Código Civil, mediante marconigrama de conformidad con lo establecido en el Art. 42 de la Ley 1306 de 2009, en caso que se desconozca los parientes deberá librarse edicto emplazatorio en un periódico de amplia circulación nacional. Finalmente, se ordenará la práctica de un dictamen médico neurológico o psiquiátrico sobre el estado del discapacitado.

Efectuada la notificación de todos los parientes y el Ministerio Público, el juez ordenará abrir a pruebas el proceso en el que se escucharan en declaración los testimonios solicitados en la demanda, a efectos de establecer no solo el estado del presunto interdicto, sino también la idoneidad de quien se propone como curador. Es igualmente recomendable decretar una visita por parte de la Asistente Social adscrita al Despacho judicial de conocimiento en la residencia del pretendido interdicto, a efectos de establecer las condiciones de vida y familiares de este; incluso , allá esta puede, de primera mano, arrojar elementos de juicio sobre las necesidades del mismo, personas que podrían ejercer la guarda sustituta, etc.

Allegado el dictamen médico neurológico o psiquiátrico sobre el estado del discapacitado, el juez deberá correrle traslado, a efectos de surtir su contradicción y de actuar conforme a las reglas del debido proceso, en este término pueden presentarse objeciones las cuales a nuestro juicio solo deberían ser por error grave respecto de la enfermedad que padece el presunto interdicto. Con todo, es claro que el auto que decide la objeción es apelable. Vencido dicho término y resueltas las objeciones (de haberlas) se debe verificar si el informe cumple con los requisitos establecidos en el artículo 586 del CGP; es decir se observa: a) Las manifestaciones características del estado actual del paciente; b) La etiología, el diagnóstico y el pronóstico de la enfermedad, con indicación de sus consecuencias en la capacidad del paciente para administrar sus bienes y disponer de ellos, y c) El tratamiento conveniente para procurar la mejoría del paciente. Si dicho dictamen cumple con estos requisitos, se procede a aprobarlo.

Luego de todo lo anterior, el juez deberá señalar fecha para evacuar las pruebas y dictar sentencia en la que dispondrá como primera medida, de conformidad a las pruebas periciales del proceso se encuentra que el padecimiento de la persona en verdad la incapacita de manera absoluta y permanente para cuidarse y administrar o manejar sus bienes, se debe declarar en interdicción por causa de discapacidad mental absoluta y que dicha persona no tiene la libre administración de sus bienes, esto a fin de que los actos jurídicos no produzcan efectos validos ante la sociedad. Inmediatamente se le deberá nombrar al curador principal y a los suplentes que se considere necesarios, fijándoles la caución establecida en el artículo 83 de la ley 1306 del 2009, a menos que por vengan exonerados de conformidad a lo establecido en el artículo 84 de la Ley 1306 de 2009 o tengan amparo de pobreza, en cuyo caso quedará al arbitrio del Juez fijar o no la Caución. Se deberá nombrar como perito avaluador a un Contador público para que confeccione Inventario y Avalúo de los Bienes del interdicto, conforme a lo establecido en el artículo 86 de la ley 1306 
del 2009, lo anterior a efectos de salvaguardar los bienes de este y de establecer un parámetro para los informes que deberá rendir el curador nombrado en relación del ejercicio de su curaduría, los cuales deberán ser en plazos no superiores a un año.

Se debe ordenar la notificación de la sentencia al público en la forma establecida en el art. 586 numeral $7^{\circ}$ del $C P C$, es decir mediante aviso que se insertará por una vez en un diario de amplia circulación nacional y debidamente inscrita en la Oficina de Registro Civil del ya declarado interdicto. Esto es importantísimo para que la sentencia de interdicción surta los efectos de ley y tenga la debida publicidad el acto, por lo que a nuestro juicio solo una vez realizada la publicación, la inscripción en el Registro del Estado Civil y aprobado el inventario de bienes, es que se le podrá dar la posesión de que trata el artículo 85 de la Ley 1306 de 2009, al designado curador principal y los suplentes, lo cual se podrá hacer en una sola diligencia.

Igualmente, como en la sentencia se ordenará que la misma se inscriba ante el respectivo funcionario del Estado civil, para que haga la anotación correspondiente en el registro del interdicto de conformidad a lo establecido en el artículo 47 de la ley 1306 del 2009 que establece que "Las decisiones de interdicción o inhabilitación y el levantamiento de las medidas se harán constar en el folio de nacimiento del registro del estado civil del afectado." Lo anterior en concordancia con el artículo $5^{\circ}$ del Decreto 1260 y el artículo $1^{\circ}$ del Decreto 2158 de 1970.

También deberá ordenarse comunicar al departamento de salud del municipio correspondiente, (o a la entidad designada para ello por la alcaldía) para que registre la sentencia en el libro de avecindamiento de personas con discapacidad mental absoluta, de conformidad con el art. 19 de la ley 1306 de 2009. Y por último es menester ordenar al Instituto de Medicina Legal que, semestralmente a partir de la ejecutoria del presente fallo, realice un seguimiento a la evolución del estado de salud del declarado interdicto.

De esta forma recomendamos que se profiera una sentencia que declare la interdicción, pues así se garantiza el cabal cumplimiento y seguimiento a los declarados en discapacidad mental.

\section{De las calidades del curador.}

La ley 1306 del 2009 trae la vieja distinción entre el guardador testamentario (Ley N 1306, 2009, art. 63), legítimo (Ley $\mathrm{N}^{\circ} 1306,2009$, art. 68) y dativo (Ley $\mathrm{N}^{\circ} 1306,2009$, art. 69), que a nuestro juicio es una reproducción de aquellas normas arcaicas y que no hemos podido superar del Ius Civitas romano. Sin embargo para el presente trabajo debemos decir que el curador al que estamos refiriéndonos es al dativo, es decir al designado por el juez de familia en el proceso de interdicción. 
Como ya se expuso, en la sentencia de interdicción debe nombrarse un curador que será la persona que tendrá a su cargo el cuidado del interdicto y la administración de sus bienes. De allí la importancia de la debida escogencia de este. En la mayoría de los casos es recomendable que se designe un curador principal y al menos un suplente, a efectos de precaver un nuevo proceso de designación de curador en caso que el principal ya no pueda seguir ejerciendo, por cualquiera de las causas legales, incluidas, su fallecimiento.

De allí que el periodo probatorio en el proceso debe ir encaminado no solo a probar el hecho que causa la incapacidad, sino que es importante que el juez logre establecer cuál de los parientes citados es el más idóneo para ejercer el cargo, normalmente el juez podrá adoptar el consenso de la familia o personas que tengan a cargo de facto al incapaz; sin embargo, y lastimosamente no siempre es así, pues en muchos casos, la designación del curador resulta ser un verdadero litigio ${ }^{123}$ y/o enfrentamiento para establecer la idoneidad de uno u otro pariente o el cónyuge, por lo que en muchos casos los jueces optan por la salida salomónica de nombrar a un auxiliar de la justicia, que no necesariamente es la más ideal ${ }^{124}$, pero que a fin de designar a alguien imparcial; resultaría más adecuada. En todo caso, luego de escogido el curador y para asegurar los resultados de la administración exige la ley, que para ejercer el cargo se debe cumplir previamente las siguientes tres formalidades: a) Otorgamiento de caución (Ley $\mathrm{N}^{\circ}$ 1306, 2009, art. 83); a menos que el juez estime que en virtud de que a quien se va a designar como curador es una de las personas exceptuadas, la exonere de pagar esta caución, es decir, el cónyuge, los ascendientes y descendientes. Además los guardadores interinos llamados por poco tiempo a servir el cargo y las sociedades fiduciarias en la mayoría de los casos (Ley N²1306, 2009, art. 84). b) Obtener el discernimiento (Ley $\mathrm{N}^{\circ} 1306,2009$, art. 85), y c) Hacer inventario solemne de los bienes del pupilo (Ley $\mathrm{N}^{\circ} 1306,2009$, art. 86). Surtidas estas exigencias, nacen para el guardador sus atribuciones propias, entre las cuales están la representación del incapaz y la administración de sus bienes.

Como habíamos manifestado, el cargo del curador implica tanto el cuidado personal del incapaz como el manejo de sus bienes, para lo cual cuenta con las facultades de representación en todos los negocios jurídicos y en todos los actos judiciales y extrajudiciales, sin embargo como es lógico, habrá algunos actos prohibidos como serían los expresamente establecidos en el artículo 93 de la ley 1306 del 2009 como son: a) Dejar de aceptar actos gratuitos desinteresados en favor del pupilo; b) Invertir en papeles al portador los dineros del pupilo. Los títulos al portador o a la orden que tenga el pupilo se liquidarán y se sustituirán por títulos nominativos; c) Celebrar cualquier acto en el que tenga algún interés el mismo curador, su cónyuge, sus parientes hasta el cuarto

123 Recordemos que se trata de proceso de jurisdicción voluntaria.

124 Por cuanto, el cuidado personal del discapacitado estará mejor en cabeza de un familia, que sea reconocido y cercano al interdicto. 
grado de consanguinidad o segundo de afinidad o de cualquier manera dé lugar a conflicto de intereses entre guardador y pupilo.

Igualmente existen algunas actuaciones que deben ser autorizadas por el juez de familia en el proceso de jurisdicción voluntaria de licencia, como son los actos contenidos en el artículo 94 de la ley 1306 del 2009. a) Las donaciones de bienes del pupilo, incluidos aquellos actos de renuncia al incremento del patrimonio del pupilo, con excepción de aquellos regalos moderados, autorizados por la costumbre, en ciertos días y casos y los dones manuales de poco valor. b) Los actos onerosos de carácter conmutativo, de disposición o de enajenación de bienes o derechos de contenido patrimonial, divisiones de comunidades, transacciones y compromisos distintos de los del giro ordinario de los negocios, cuya cuantía supere los cincuenta (50) salarios mínimos legales mensuales.

Sobre ese punto vale la pena establecer que afortunadamente ya se eliminó la necesidad de la subasta pública en estos procesos que hacia dispendioso el trámite de venta; asimismo vale la pena aclarar que esta licencia también podrá ser expedida por el notario con la entrada en vigencia del artículo 617 del Código General del Proceso, reglamentado por el decreto 1664 del 2015 ; c) Las operaciones de crédito distintas de las mencionadas en el literal a) del artículo siguiente y el otorgamiento de garantías o fianzas y constitución de derechos reales principales o accesorios sobre bienes del pupilo, en favor de terceros, que no corresponda al giro ordinario de los negocios, en cuantía superior a los cincuenta (50) salarios mínimos legales mensuales. d) La enajenación de los bienes esenciales de una actividad empresarial cualquiera que sea su valor, salvo que se trate de la reposición de activos. Las operaciones de reposición de activos productivos deberán constar por escrito y los dineros provenientes de la enajenación no podrán ser destinados a otros fines sin autorización judicial. e) El repudio de los actos gratuitos interesados o modales en favor del pupilo. Las herencias podrán ser aceptadas libremente, pero se presumirá de Derecho que han sido aceptadas con beneficio de inventario. f) La imposición de obligaciones alimentarias y cualquier otra prestación de carácter solidario a favor de familiares o allegados. En ningún caso se destinarán bienes del pupilo a atender necesidades suntuarias de los beneficiarios.

Podemos observar, entonces, que las reglas relativas a la administración de los bienes del incapaz interdicto son similares a las de la patria potestad, respecto de los bienes y derechos del curador frente al pupilo; incluso tendrá derechos a una parte nunca superior a una décima de los frutos netos del patrimonio del pupilo, más los gastos necesarios para el desempeño de la gestión (Ley $N^{\circ} 1306,2009$, Art. 99).

De la misma manera, el curador responderá siempre por la culpa levísima como los padres de familia respecto de la administración de los bienes de los hijos. 
Cesar Andrés Tirado Pertúz, Carlos Eduardo García Granados

\section{Principales cambios al proceso de interdicción en el código general del proceso}

En esencia, el Código General del Proceso mantuvo la estructura antes explicada que venía ya desde la Ley 1306 del 2009 en el articulado del Código. El artículo 586 del CGP frente al artículo 659 del Código de Procedimiento Civil, trae las siguientes novedades:

- Practicadas las pruebas, se dicta sentencia. En ella se nombra guardador y si tiene bienes, se ordena confeccionar un inventario de ellos por un auxiliar de la justicia a menos que se declare bajo la gravedad de juramento que el interdicto no tiene bienes, en cuyo caso el juez puede exonerar al curador de esta formalidad para su posesión sin entrega de bienes. A nuestro juicio el juez deberá hacer la advertencia que si aparecen bienes o por cualquier causa el incapaz adquiere bienes (bien sea donaciones o herencias) deben ser denunciados en el proceso y hacerse dicho inventario. Los honorarios estarán a cargo del incapaz y si no tiene recursos debe sufragarlos el Instituto Colombiano de Bienestar Familiar.

- Si el guardador debe prestar caución, una vez prestada se le dará posesión y se le hará entrega de los bienes inventariados conforme al artículo 86 de la ley. La remisión al artículo 44 es errónea, y ello se debe a que se trasladó al código el artículo 87 de la ley 1306, donde igualmente está erróneamente citado el artículo 44.

- La diligencia de entrega la realizará el juez o su comisionado, diligencia a la que deberán asistir éstos y el perito que participó en la elaboración del inventario. La ausencia del perito no impedirá que se realice la diligencia pero lo hará responsable de los daños que pueda ocasionar.

- El guardador puede objetar el inventario dentro de los cinco días siguientes a la recepción de los bienes. Las objeciones se tramitan como incidente, y al resolverlo se aprobará el inventario.

- Se pueden decretar las medidas de protección personal que el juez considere necesarias para el discapacitado, en este caso no pueden confundirse con las medidas innominadas, ya que estas como se explicó anteriormente son unas medidas especiales de carácter personal.

- Rehabilitación del interdicto.- El artículo 687, establece que para la rehabilitación del interdicto se aplicará el procedimiento de la interdicción, sin que haya lugar a la citación de posibles interesados.

\section{Discusión.}

En relación al análisis del proceso judicial de interdicción, debemos explicar que en la práctica son procesos que, teóricamente, no deberían superar los 6 meses en los despachos judiciales, pues deben tener prioridad, ya que se trata de sujetos de especial protección por parte del estado y 
la regulación internacional. Lamentablemente, mucho de los casos de interdicción, por la congestión de los despachos judiciales tardan demasiado, llegándose a dar el caso que al momento de proferir sentencia, ya el interdicto ha fallecido. En todo caso, el problema es meramente humano y de desconocimiento de la nueva normatividad, pues en muchas ocasiones los jueces de familia aún tienen la conciencia de tratar al discapacitado como paciente y no como sujeto de derechos, lo que dificulta la aplicación de la ley 1306 del 2009.

La escogencia de un curador idóneo para el interdicto resulta ser la principal dificultad para el feliz término de los procesos de interdicción, sin embargo, consideramos que en estos casos, el juez de familia debería tener un papel más activo, revisando minuciosamente las cualidades de los que se proponen y proferir una decisión de fondo, incluso designando un curador provisional, en tanto se define definitivamente la curaduría; lo que sucede es que en muchos casos la declaratoria de interdicción urge, para temas comerciales o peor aún personales como una simple afiliación al sistema de salud o inscripción en algún programa gubernamental.

En todo caso, este papel activo es reclamado, incluso, por el parágrafo primero del artículo 281 del CGP, en aras de lograr una protección adecuada a la persona con discapacidad mental, mediante el fallo extra y ultra petita. Por ejemplo, si la persona que se pretende designar guardador no reúne las condiciones de idoneidad, o reuniéndolas, pudiese estimarse insuficiente su sola presencia, designar a un familiar de aquellos que previamente se citó en el proceso, para que asuma dicho rol.

\section{CONCLUSIONES}

Lo más importante en el estudio de esta temática es entender que se trata de un área que debe ser objeto de constante revisión, pues la normatividad debe ir avanzado conforme a la ciencia y las habilidades de los "discapacitados mentales", ya que la ciencia médica avanza a pasos agigantados en relación a la recuperación de aquellos que no cuentan con todas las facultades motoras de las que disponemos los "normales".

Es así como actualmente no todo tipo de invalidez, o incapacidad tendrá como consecuencia inevitable la declaratoria de interdicción, pues existen muchas personas con ciertas limitaciones de orden físico o neurológico, que perfectamente pueden administrarse a sí mismos y disponer de sus bienes con la lucidez exigida por la ley. De allí que recientemente la Corte Constitucional haya establecido acertadamente que "No debe confundirse la situación de discapacidad con la invalidez en el contexto de la normativa de seguridad social." (Corte Constitucional sentencia T933/13 Jorge Ignacio Pretelt Chaljub). Por eso la primera conclusión de este trabajo es que la discapacidad mental y los procesos de interdicción son temas inacabados que en un futuro no muy lejano deberán ser objeto de nueva regulación. 
De otra parte, la crítica inicial en relación a acudir a la instancia procesal solo cuando existe interés económico, encuentra asidero en las implicaciones jurídicas del proceso, pues más que el cuidado personal y atención al incapaz, a la familia le interesa el sostenimiento patrimonial del interdicto. La sociedad colombiana no ha podido superar los conceptos anacrónicos frente a los discapacitados, en ocasiones los ocultan de la vecindad, o simplemente los minimizan a una atracción en las reuniones familiares. De allí que, solo se acuda a estos procesos cuando se evidencia una necesidad económica, tan sencilla como es, por ejemplo, la reclamación de una pensión de sobreviviente, o el manejo de acciones comerciales de determinada sociedad en la que hace parte el interdicto, la representación judicial, entre muchos otros casos.

Creemos que la aplicación del procedimiento establecido en la ley 1306 del 2009 y hoy en el Código General del Proceso implica una humanización del discapacitado mental, que se encuentra acompasado a la óptica del bloque de constitucionalidad que trajo consigo la Carta de 1991 y que infortunadamente solo se ha logrado aplicar por partes, quizás porque no resulta políticamente apetitoso el tema para nuestros distinguidos legisladores. Habrá que ver que depara el futuro jurídico respecto a estos temas. Nos atreveríamos a avizorar que la declaración de interdicción podrá hacerse por escritura pública, lógicamente con fundamentos en pruebas científicas como los certificados médicos, siendo necesario que se asista al juez de familia únicamente para efectuar el nombramiento del curador, pero ya con el instrumento público se tendría una prueba que serviría para muchísimos actos en los que se requiere dicha declaración.

\section{REFERENCIAS BIBLIOGRÁFICAS}

ALEXY, Robert. (1993.) Teoría de los derechos fundamentales. Madrid. Centro de Estudios Constitucionales.

ANGARITA Gómez, Jorge (2005) Lecciones de Derecho Civil. Tomo I Personas y representación de incapaces. Editorial Temis S.A. Santa Fe de Bogotá, D.C., Colombia. Cuarta Edición.

Constitución Política de Colombia de 1991.

Convención sobre la protección de Derechos a Personas con Discapacidad, de las Naciones Unidas, del 13 de diciembre de 2006, incorporada en nuestro ordenamiento mediante la ley 1346 del 2009.

INSTITUTO COLOMBIANO DE BIENESTAR FAMILIAR - ICBF; CONCEPTO 29 DE 2014 (Marzo 10). Código Civil Colombiano.

Código de la Infancia y la Adolescencia. 
Código General del Proceso.

ECHEVERRIA Esquivel, Mario y ECHEVERRIA Acuña Mario (2010) Compendio de Derecho Romano. Editorial Edgardo Pallares Bossa. Santa Fe de Bogotá, D.C., Colombia. Primera Edición

ENCICLOPEDIA Jurídica Omeba, (1990) tomo XIV, DRISKILL S.A., Buenos Aires.

GUTIÉRREZ Sarmiento, Carlos (2017) Manual de Procesos de Familia. Universidad Externado de Colombia. Santa Fe de Bogotá, D.C., Colombia. Cuarta Edición.

LAFONT Pianetta, Pedro (2010) Derecho de Familia. Derecho Marital, Filial, Addenda Reforma de la ley 1306 de 2009. Ediciones del Profesional. Santa Fe de Bogotá, D.C., Colombia.

LÓPEZ Blanco, Hernán Fabio (2009). (1996). Instituciones de Derecho Procesal Civil Colombiano Tomo II Parte Especial. DUPRE Editores. Santa Fe de Bogotá, D.C., Colombia. Novena Edición.

LÓPEZ Medida, Diego, (2004) El derecho de los Jueces, Ediciones Universidad de los Andes, Universidad Nacional de Colombia, Bogotá.

Ley 1306 del 2009. Por la cual se dictan normas para la Protección de Personas con Discapacidad Mental y se establece el Régimen de la Representación Legal de Incapaces Emancipados.

PARRA Benitez, Jorge (2011) El nuevo régimen de incapaces en el derecho colombiano, ley 1306 del 2009. Colección monografías No. 15. Grupo Editorial Ibáñez. Santa Fe de Bogotá, D.C., Colombia.

PETITE, Eugene (1971) Tratado Elemental de derecho Romano, Editorial Nacional, México D.F.

QUIROZ Monsalvo, Aroldo (2014) Manual Civil. Tomo V. Ediciones Doctrina y Ley Ltda. Santa Fe de Bogotá, D.C., Colombia. Tercera Edición.

SIERRA Rincon, Néstor (1991) Procesos Ante los Jueces de Familia. Ediciones del Profesional. Santa Fe de Bogotá, D.C., Colombia. Primera Edición.

UPRIMNY, Rodrigo. 2000. "Justicia Constitucional, Derechos Sociales y Economía: Un análisis teórico y una discusión de las sentencias de UPAC" en Pensamiento Jurídico, № 13 
Cesar Andrés Tirado Pertúz, Carlos Eduardo García Granados

VALENCIA Zea, Arturo y ORTIZ Monsalve Álvaro, (1994) Derecho Civil Tomo I parte General y Personas. Editorial Temis S.A. Santa Fe de Bogotá, D.C., Colombia. Decimotercera Edición.

ZAGREBELSKY, Gustavo, (2006) Jueces constitucionales (trad. de Miguel Carbonell); publicado en la Revista Ibero Americana de Derecho Procesal Constitucional № 6. Editorial Porrúa, SA de CV, México.

\section{NICHO JURISPRUDENCIAL ${ }^{125}$ :}

Corte Constitucional sentencia T-307 de 1993, M.P. Dr. Eduardo Cifuentes Muñoz.

Corte Constitucional sentencia T-378 de 1997, M.P. Dr. Eduardo Cifuentes Muñoz.

Corte Constitucional sentencia C-478 del 2003 M.P. Dra. Clara Inés Vargas Hernández.

Corte Constitucional sentencia C- T-1103 de 2004 M.P. Dra. Clara Inés Vargas Hernández.

Corte Constitucional sentencia T-1221 de 2004 M.P. Dr. Alfredo Beltrán Sierra.

Corte Constitucional sentencia T-941 del 2005 M.P. Dra. Clara Inés Vargas Hernández.

Corte Constitucional sentencia T-933 de 2013 M.P. Dr. Jorge Ignácio Pretelt C.

Corte Constitucional sentencia T-026 de 2014 M.P. Dr. Nilson Pinilla Pinilla.

Corte Constitucional sentencia C-021 de 2015 M.P. Dr. Mauricio González Cuervo.

125 No se encuentra en esta reseña, todo el acervo jurisprudencial sobre esta temática. Enunciamos aquí las más representativas para efectos de este trabajo 